\title{
Critical Overview of HER2 Assessement in Bladder Cancer: What Is Missing for a Better Therapeutic Approach?
}

\author{
ANCA MARIA CIMPEAN ${ }^{1}$, VALERIA TARLUI ${ }^{1}$, ALIN ADRIAN CUMPĂNAȘ ${ }^{2}$, \\ SORIN BOLINTINEANU ${ }^{3}$, ANDREI CUMPĂNAȘ ${ }^{1}$ and MARIUS RAICA ${ }^{1}$ \\ ${ }^{1}$ Department of Microscopic Morphology/Histology, Angiogenesis Research Center, \\ ${ }^{2}$ Department of Ortophedic Surgery, Traumatology and Urology, ${ }^{3}$ Department of Anatomy, \\ "Victor Babes" University of Medicine and Pharmacy Timisoara, Timisoara, Romania
}

\begin{abstract}
Background/Aim: To assess the concordance between IHC and FISH and its influence on tumor type, grade and lympho-vascular invasion (LVI). Materials and Methods: HER2 immunohistochemistry (IHC) to 45 cases of bladder carcinoma, followed by fluorescent in situ hybridization (FISH) were applied. Results: $31.12 \%$ cases were IHC positive. Less than 35\% of HER2-negative cases presented LVI and this percent increased to $54.54 \%$ for +1 HER 2 cases. LVI increases up to $57.14 \%$ for +2 HER 2 cases and slightly decreased for +3 HER2 cases to $42.85 \%$. IHC/FISH concordance was found for $73.34 \%$ cases but $31.57 \%$ were previously negative and $36.36 \%$ scored as +1 by IHC had gene amplification as shown by FISH analysis. T3 was correlated with HER2-IHC $(p=0.05)$ and HER2-FISH ( $p=0.01$ ). Conclusion: Improved HER2 assessement is needed for urothelial carcinomas. HER2-IHC scored as 0-2 should be validated by and reclassified according to FISH analysis.
\end{abstract}

Between tyrosine kinase family members, human epidermal growth factor receptor 2 (also known as HER2, c ERB B2) is heterogeneously expressed in a variety of human malignancies such as breast (1), gastric (2), ovarian (3), renal (4) or bladder cancer (5). Humanized monoclonal antibody-based therapies targeting HER2 overexpression have been certified by Food and Drug Administration (FDA) and are extensively applied in clinical practice for the treatment of metastatic breast cancer. For other malignancies, monoclonal antibodies targeting HER2 overexpression have not represented a widely accepted therapeutic option due to controversial results reported in the

Correspondence to: Prof. Anca Maria Cimpean, Department of Microscopic Morphology/Histology, Angiogenesis Research Center, Piata Eftimie Murgu 2, 300041 Timisoara, Romania. Tel: +40 720060955, e-mail: ancacimpean1972@yahoo.com

Key Words: HER2, bladder cancer, immunohistochemistry, fluorescent in situ hybridization. literature (6-8). Among malignancies with certified HER2 overexpression, bladder cancer has limited therapeutic options because of controversies regarding the impact of targeted therapies on patient's survival. Assessment of HER2 overexpression and gene amplification is controversial, no wellestablished protocol has been used for the stratification of patients with HER2 positive bladder cancers and their inclusion into a particular group which can benefit from trastuzumab therapy. Recently, Tschui and his team (9), tried to identify some morphological features of HER2 overexpressing bladder cancer and reported that the micropapillary type is predominant amongst them (9). Like in other cancer types, the usual method applied to highlight HER2 overexpression is immunohistochemistry, a simple and reliable method to detect protein overexpression in tumor cells (10). Different immunohistochemistry protocols are being applied for breast and gastric cancer (10-12). HER2 immunohistochemistry is applied mostly to the primary tumor and to a lesser extend to the corresponding metastasis (13). Also, limited use of fluorescent in situ hybridization (FISH) restricted to those cases classified as "equivocal" (HER2, +2) by immunohistochemistry contributes to misdiagnosed HER2 negative cases in breast and gastric cancers. Recently, several papers reported that antiHER2 therapy should not be recommended unless true evaluation of HER2 protein expression and gene amplification, this being sustained by previous implementation of the 2013 ASCO/CAP updated guidelines certified to have an increased positive impact on HER2 classification for breast cancers initially classified as having equivocal HER2 IHC results. These new guidelines significantly increased the benefit of HER2targeted therapy (14-16). In bladder cancer, the widely accepted fact is that HER2 overexpression characterizes the papillary variant (9). Fluorescent and/or chromogen in situ hybridization methods are recommended in order to validate HER2 immunohistochemistry results, especially for +2 positive cases in bladder cancer. Because of these restricted recommendations no data are available about the evaluation of HER2 gene amplification by FISH, for cases noted as +1 by 
immunohistochemistry. HER2 protein expression remains a controversial issue regarding score assessment of immunohistochemical specimens. Patients with +3 score are directly enrolled into trastuzumab therapy, while for patients with +2 score, additional ISH methods are recommended for gene amplification detection. For +1 HER2-positive cases, the immunohistochemical staining exists but is now considered irrelevant and there are no recommendations for its verification by FISH. Despite the fact that +1 HER 2 score is considered "low", the protein expression exists however, its impact on the development of drug resistance or on the HER2 phenotype switch between primary tumor and its corresponding lymph node metastasis, as was previously reported in breast cancer, remains unknown (17). Recently the same variability was reported by Park and co-workers in gastric cancer who recommended repeating HER2 assessment for patients with advanced gastric cancer whose primary tumor was initially HER2-negative (18).

The aim of this study was to evaluate neglected aspects of HER2 assessment in bladder cancer, related to tumor type, grade and lympho-vascular invasion. In particular, we aimed to evaluate by FISH all cases assessed for HER2 overexpression by immunohistochemistry, independently from the IHC score. This may increase accuracy in the identification of HER2 positive cases and a better future stratification and selection of patients suitable for trastuzumab therapy.

\section{Materials and Methods}

Ethics approval and consent to participate. Ethics Commitee of Victor Babes University of Medicine and Pharmacy Timisoara approved the use of archival parraffin blocks and data regarding histopathology of the tumors for the present study.

Samples description. Fifty cases of archival paraffin embedded tissues of bladder cancer were selected. Cases were previously characterized regarding tumor type, $\mathrm{T}$ parameter, grade and presence of lympho-vascular invasion. Two independent histopathologists reviewed the cases and excluded five of them because of poor primary processing (not enough material or improper fixation highlighted by negative immunohistochemistry for Vimentin, clone V9). After re-evaluation, we performed a $3 \mu \mathrm{m}$ serial section from each of the forty five cases to be used for immunohistochemistry and in situ hybridisation.

Immunohistochemical analysis. All steps of immunohistochemical staining were performed using a fully automated workflow provided by BOND Max Autostainer by using BOND ${ }^{\mathrm{TM}}$ ORACLE $^{\mathrm{TM}}$ Human Epidermal Growth Factor Receptor 2 (HER2) Immunohistochemical System (Leica MicroSystems, NewCastle, UK) compatible for this automated system and approved by FDA in 2012.

In situ hybridisation was manually performed with PathVysion HER-2 DNA kit and VYSIS FISH probes, following the manufacturer's protocol (Abbott Molecular, USA). Briefly, the sections were dewaxed in xylene for $10 \mathrm{~min}$ at room temperature, treated with alchool and dried. These steps were followed by a pretreatment step using Preatreatment solution at $80^{\circ} \mathrm{C}$ for $30 \mathrm{~min}$. Denaturation of specimens DNA was performed by immersion of the slide in the denaturing solution at $72 \pm 1^{\circ} \mathrm{C}$ for $5 \mathrm{~min}$, followed by dehydration steps in alcohol succesive bathes with a gradually increasing concentration from 70 to $100 \%$. Ten $\mu$ of probe mixing was applied to the target area of each specimen and the hybridisation step started by using Dako Hybridiser (DAKO, Cytomation, San Francisco, USA), for $18 \mathrm{~h}$ at $37^{\circ} \mathrm{C}$. Post hybridisation step included staining with DAPI and storage of the slides in a dark place until used according to the manufacturer's instructions.

Data interpretation. For interpretation of both immunohistochemical and FISH results, we used the standardised scores applied for the assessement of HER2-positive breast cancer. We identified the concordance rate and discordances between IHC and FISH results and we carefully evaluated gene amplification in all cases, including +1 HER2 positive cases.

Statistical analysis was performed by using SPSS 17 software (IBM Corporation, New York, NY, USA) including correlation tests. A $p$-value of $<0.05$ was considered significant.

\section{Results}

Pathology of the FFPE bladder specimens. Histopathology evaluation identified a study group composed of one bladder papilloma (2.22\%), 3 squamous cell carcinomas (6.66\%), 4 cases of adenocarcinomas (8.88\%) and 37 cases of invasive urothelial carcinomas (82.23\%). Except for the papilloma case, we assessed $\mathrm{T}$ parameter and grading $(\mathrm{G})$ for each specimen. Staging of primary tumors $(\mathrm{T})$ in bladder cancer identified T1 in seven cases (15.9\%), T2 in 3 cases $(6.82 \%)$, T3a in 12 cases $(27.29 \%)$ and T3b in 22 cases (50\%). Two cases were graded as $\mathrm{G} 1,12$ cases as $\mathrm{G} 2$ and 30 cases had a G3 score. Nineteen (42.23\%) out of 45 cases presented lympho-vascular invasion observed on routine stained specimens. All data are summarized in Figure 1 and overviewed statistical data are presented in Table I.

Assessment of HER2 overexpression by immunohistochemistry. All cases were analysed by immunohistochemistry for HER2 protein expression. We scored the membrane restricted expression. About one third of cases (31.12\%) showed positive expression for HER 2 oncoprotein scored as +2 and +3 . Nineteen cases did not express HER2 (scored as 0 ) while 11 cases were evaluated as +1 HER 2 (reported by all known scoring systems as being negative, too). From seven cases scored as +3 for HER 2 six were staged as T3A (3) or T3B (3), only one case being staged as T1. Cases scored as +2 for HER 2 by immunohistochemistry $(n=7)$ were staged as follows: 3 cases as T1, 3 cases as T3A and one case as T3B. Eleven cases were scored as having a +1 HER 2 score assessed by immunohistochemistry. For this group, six cases were characterised as $\mathrm{T} 3 \mathrm{~B}$, two cases as $\mathrm{T} 3 \mathrm{~A}$ and $\mathrm{T} 2$, respectively and one case as T1. A dynamic change was registered 
Table I. Descriptive statistics of cases.

\begin{tabular}{lccccc}
\hline & N & Minimum & Maximum & Mean & Std. Deviation \\
\hline Histology & 45 & 1.00 & 4.00 & 1.3111 & 0.73306 \\
$\mathrm{~T}$ & 45 & 0.00 & 3.50 & 2.8000 & 0.99659 \\
$\mathrm{G}$ & 45 & 0.00 & 3.00 & 2.5778 & 0.69048 \\
$\mathrm{LVI}$ & 45 & 0.00 & 1.00 & 0.4222 & 0.49949 \\
IHC.HER2 & 45 & 0.00 & 3.00 & 1.0222 & 1.11781 \\
FISH.HER2 & 45 & 0.00 & 4.00 & 1.1778 & 1.31924 \\
Valid N (listwise) & 45 & & & & \\
\hline
\end{tabular}

Table II. Case distribution according with HER2 score assessed by IHC and FISH respectively.

\begin{tabular}{lcccccc}
\hline HER2 score & IHC & $\%$ & ISH & $\%$ & $\Delta$ IHC/ISH & \\
\hline 0 & 20 & 44.44 & 22 & 48.89 & 2 & 4.45 \\
1 & 11 & 24.44 & 5 & 11.11 & 7 & 13.33 \\
2 & 7 & 15.56 & 7 & 15.56 & 0 & 0.00 \\
3 & 7 & 15.56 & 11 & 24.44 & 4 & 8.88 \\
Total & 45 & 100 & 45 & 100 & & \\
\hline
\end{tabular}

regarding correlation between lympho-vascular invasion and differential expression of HER2. In the groups considered as negative for HER2-IHC with a 0 score, less than $35 \%$ of cases presented lympho-vascular invasion, and this percent abruptly increased to $54.54 \%$ for negative cases scored as +1 . The percent of cases with lympho-vascular invasion increased up to $57.14 \%$ for +2 HER 2 positive cases and slightly decreased in the +3 HER 2 positive group to $42,85 \%$.

The papillary type of urothelial cancer had the highest and constant expression of HER 2 by immunohistochemistry (all cases being positive), confirmed by a high (+3 HER2) gene amplification assessed by FISH.

Impact of concordances and discordances between IHC and FISH analysis in bladder cancer. Usually, for breast cancer, the recommendation to perform FISH is given only for cases scored as +2 by HER2-IHC. No precise recommendations and protocol interpretation is currently given for HER2 assessment in urothelial cancer. Few studies have applied FISH to all cases despite of their previous classification by HER2 immunohistochemical scoring. For urothelial cancer scattered data have suggested that FISH is superior to immunohistochemistry and recommend to be performed in all cases, but this is not widely accepted.

We performed FISH to all cases of urothelial carcinomas focusing on those which are grouped as 0 and +1 after HER2-IHC. Differences between IHC and FISH are summarized in Table II. Concordance between immunohistochemistry and FISH was registered in 33 cases
Table III. Procentual distribution of concordances and discordances between IHC and FISH analysis.

\begin{tabular}{lcc}
\hline HER2 & No. & $\%$ \\
IHC/ISH & & \\
Concordance $v s$. discordance & & \\
\hline $0 / 0$ & 14 & 33.34 \\
$0 / 1$ & 1 & 2.22 \\
$0 / 2$ & 1 & 2.22 \\
$0 / 3$ & 3 & 6.67 \\
$1 / 0$ & 7 & 15.56 \\
$1 / 1$ & 2 & 4.44 \\
$1 / 2$ & 1 & 2.22 \\
$1 / 3$ & 1 & 2.22 \\
$2 / 0$ & 0 & 0.00 \\
$2 / 1$ & 2 & 4.44 \\
$2 / 2$ & 2 & 4.44 \\
$2 / 3$ & 3 & 6.67 \\
$3 / 0$ & 0 & 0.00 \\
$3 / 1$ & 0 & 0.00 \\
$3 / 2$ & 3 & 6.67 \\
$3 / 3$ & 4 & 8.89 \\
Total & 45 & 100 \\
\hline
\end{tabular}

Table IV. Lymphovascular invasion (LVI) related with T parameter and IHC-HER2 score.

\begin{tabular}{lccccc}
\hline & T1 & T2 & T3a & T3b & LVI + \\
\hline +3 HER2-IHC & 1 & 0 & 3 & 3 & $42,85 \%$ \\
+2 HER2-IHC & 3 & 0 & 3 & 1 & $57,14 \%$ \\
+1 HER2-IHC & 1 & 2 & 2 & 6 & $54,54 \%$ \\
0 HER2-IHC & 2 & 1 & 5 & 11 & $31,57 \%$ \\
Total & 7 & 3 & 13 & 21 & 44 \\
\hline
\end{tabular}

$(73,34 \%)$. The most unexpected finding was the distribution of another 12 cases regarding discrepancies between IHC and FISH. In the group scored as negative by IHC, we detected 6 cases having HER 2 gene amplification by FISH. They represented about $31,57 \%$ of cases previously classified as negative by the use of immunohistochemistry, only. From these six cases, 4 showed high amplification noted as +2 and +3 by HER2-FISH scoring. In the cases with +1 HER2-IHC, $36,36 \%$ of cases had FISH amplification (from 4 cases, 2 had low amplification scored as 1 and another 2 had 2 or 3). Most of the researchers usually focus on the +2 HER2-IHC group, which is still controversial in HER2 evaluation even in other cancer types. In our study, all seven cases showed gene amplification by FISH (two cases with low amplification and other 5 being highly amplified, Figure 2). All cases from the +3 HER2-IHC group had high gene amplification by FISH (Table III). 

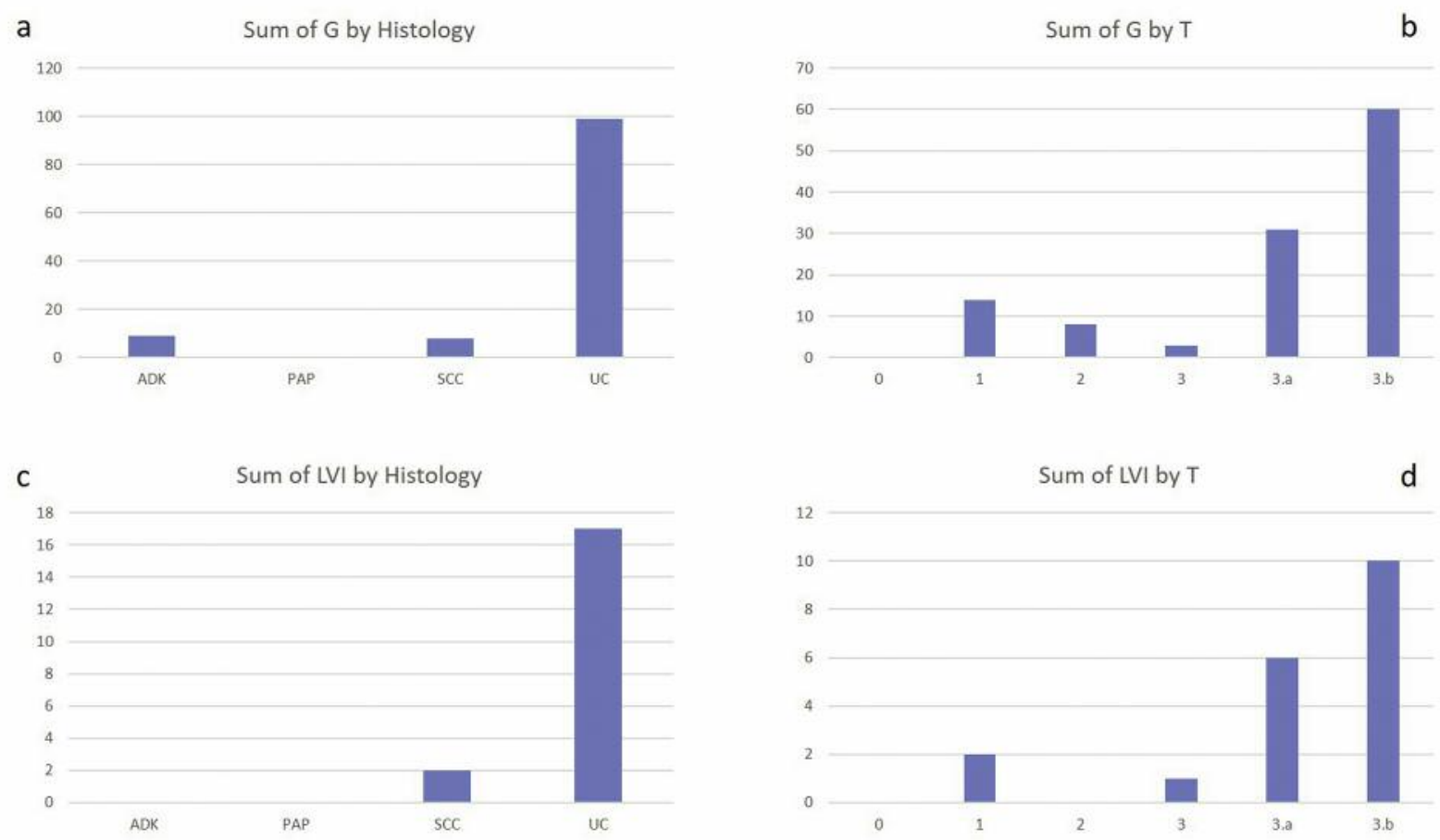

Figure 1. Graphical distribution of case numbers by their relationship with histology, $G$, $T$, and lymphovascular invasion (LVI).

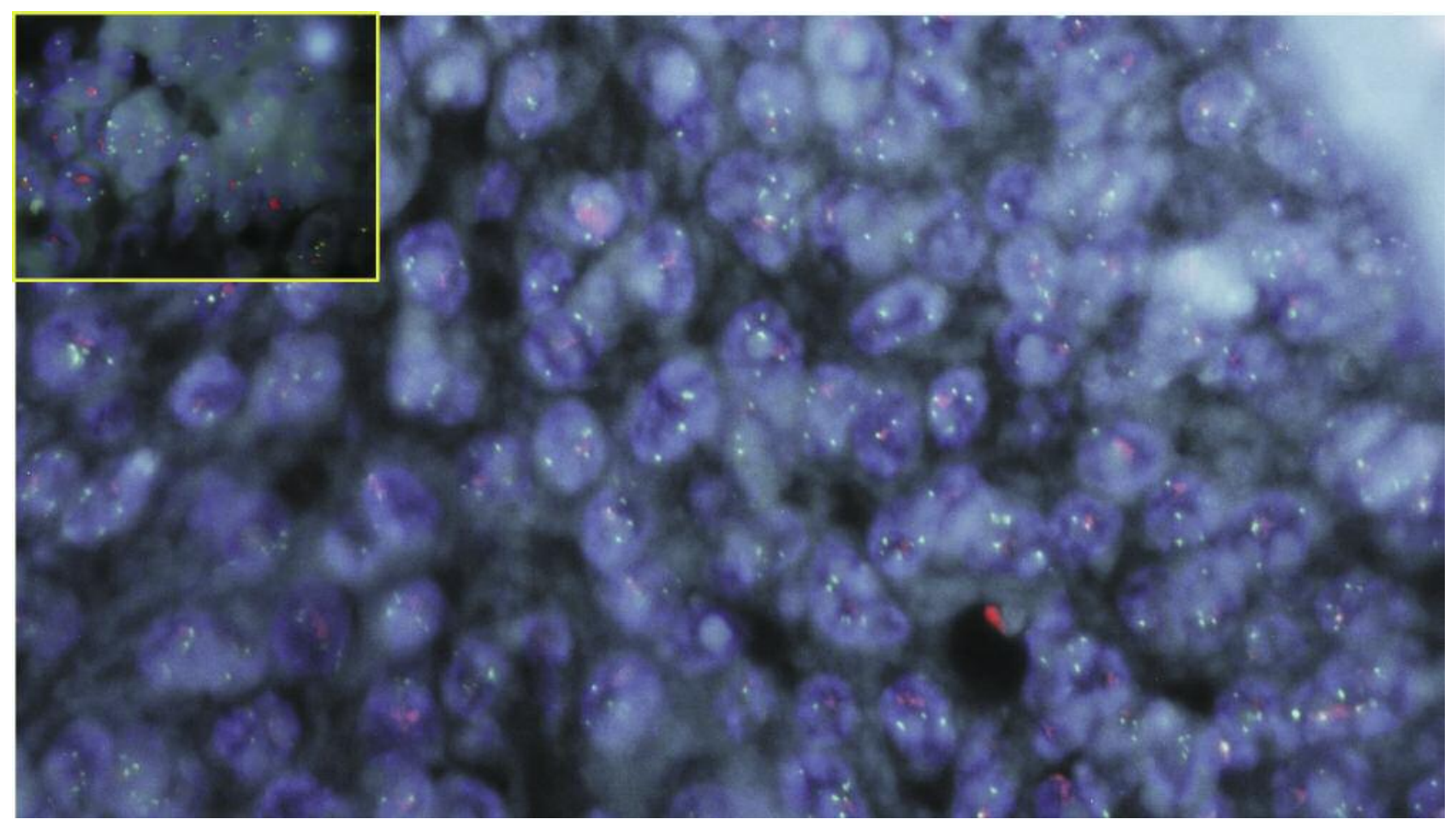

Figure 2. Fluorescent in situ hybridisation confirmed gene amplification for cases scored as negative (score 0 and +1$)$ for HER2 immunohistochemistry. The most intriguing cases were those with score 0 and high amplification detected by FISH as it happened for the present case. 
Table V. Analysis of cases declared as negative based on protocols for IHC interpretation of HER2 and reclassified according to gene amplification assessed by FISH.

\begin{tabular}{|c|c|c|c|c|c|c|c|}
\hline & & Histology & $\mathrm{T}$ & G & LVI & IHC.HER2 & FISH.HER2 \\
\hline \multirow[t]{3}{*}{ Histology } & Pearson Correlation & 1 & 0.283 & -0.188 & -0.279 & $-0.535^{*}$ & 0.080 \\
\hline & Sig. (1-tailed) & & 0.200 & 0.289 & 0.203 & 0.045 & 0.407 \\
\hline & $\mathrm{N}$ & 12 & 12 & 12 & 12 & 12 & 12 \\
\hline \multirow[t]{3}{*}{$\mathrm{T}$} & Pearson Correlation & 0.283 & 1 & 0.009 & $0.641 *$ & 0.025 & $0.670^{*}$ \\
\hline & Sig. (1-tailed) & 0.200 & & 0.490 & 0.017 & 0.470 & 0.012 \\
\hline & $\mathrm{N}$ & 12 & 12 & 12 & 12 & 12 & 12 \\
\hline \multirow[t]{3}{*}{ G } & Pearson Correlation & -0.188 & 0.009 & 1 & 0.069 & 0.237 & -0.020 \\
\hline & Sig. (1-tailed) & 0.289 & 0.490 & & 0.420 & 0.242 & 0.477 \\
\hline & $\mathrm{N}$ & 12 & 12 & 12 & 12 & 12 & 12 \\
\hline \multirow[t]{3}{*}{ LVI } & Pearson Correlation & -0.279 & $0.641^{*}$ & 0.069 & 1 & 0.196 & 0.392 \\
\hline & Sig. (1-tailed) & 0.203 & 0.017 & 0.420 & & 0.282 & 0.117 \\
\hline & $\mathrm{N}$ & 12 & 12 & 12 & 12 & 12 & 12 \\
\hline \multirow[t]{3}{*}{ IHC.HER2 } & Pearson Correlation & $-0.535^{*}$ & 0.025 & 0.237 & 0.196 & 1 & -0.057 \\
\hline & Sig. (1-tailed) & 0.045 & 0.470 & 0.242 & 0.282 & & 0.434 \\
\hline & $\mathrm{N}$ & 12 & 12 & 12 & 12 & 12 & 12 \\
\hline \multirow[t]{3}{*}{ FISH.HER2 } & Pearson Correlation & 0.080 & $0.670^{*}$ & -0.020 & 0.392 & -0.057 & 1 \\
\hline & Sig. (1-tailed) & 0.407 & 0.012 & 0.477 & 0.117 & 0.434 & \\
\hline & $\mathrm{N}$ & 12 & 12 & 12 & 12 & 12 & 12 \\
\hline
\end{tabular}

*Correlation is significant at the 0.05 level (1-tailed).

Based on FISH results we reclassified HER2 positive cases and the percent of positive cases increased from $31.12 \%$ (found by IHC) to $51.1 \%$ of cases.

Statistical analysis was performed between HER2-IHC and HER2-FISH, T parameter and G. A significant statistical correlation was found between T3 parameter and both HER2-IHC $(p=0.05)$ and HER2-FISH $(p=0.01)$. As observed from these data, correlation between T and HER2-FISH was significantly stronger compared with those between $\mathrm{T}$ and HER2-IHC. Case distribution according to $T$ parameter, HER2-IHC score and lympho-vascular invasion are summarized in Table IV. It seems that HER2 has no influence on $\mathrm{G}$ parameter, this also being supported by the lack of a significant correlation between these two parameters in the present study.

Moreover, when we performed statistical analysis restricted to those 12 cases which were previously considered as negative IHC.HER 2 score $(0,1)$ or score 2 but with amplification highlighted by FISH, we found that T3 parameter was strongly associated with lympho-vascular invasion (LVI) and FISH-IHC2 amplification, while histology proved to be correlated with IHC.HER2 overexpression only (Table V). When we exclusively analyzed cases classified as having score 0 by IHC we found that LVI is significantly correlated with FISH.HER2 amplification and not with IHC.HER2 score or any other parameters (Table VI).
Table VI. Significant relationship between LVI and FISH.HER2 amplification for cases previously scored as 0 by IHC.HER2.

\begin{tabular}{llcc}
\hline & & LVI & FISH.HER2 \\
\hline LVI & Pearson Correlation & 1 & $0.905^{*}$ \\
& Sig. (1-tailed) & & 0.048 \\
& N & 6 & 6 \\
FISH.HER2 & Pearson Correlation & $0.905^{*}$ & 1 \\
& Sig. (1-tailed) & 0.048 & \\
& N & 6 & 6 \\
\hline
\end{tabular}

*Correlation is significant at the 0.05 level (1-tailed).

\section{Discussion}

Receptor tyrosine-protein kinase (RTKs) erbB-2 (CD340) is frequently known as HER 2 . It is a proto-oncogene encoded by the $E R B B 2$ gene in humans and is part of a large family of human epidermal growth factor receptors (together with HER1, HER3 and HER4) (19). Thirty years after its discovery and characterisation in breast cancer cells (20), HER2 represents a therapeutic target for more than $30 \%$ of metastatic breast cancer cases $(21,22)$ but the function of this receptor is not fully elucidated yet. The plasticity of this molecular target to form heterodimers not only with other members of the EGFR family but also with other related RTKs seems to be one of the mechanisms responsible for 
resistance development following specific treatment with humanized monoclonal antibodies against HER2 such as trastuzumab (23).

While for breast cancer there are already developed therapies able to decrease development of drug resistance and to improve the efficiency of targeted therapy against HER2 (24, 25), for other cancer types the expression and role of HER2 in progression and metastasis are not fully elucidated and thus a HER2 based therapy is not well accepted for gastric cancer for example (26).

Urothelial malignancies are among the most neglected cancers regarding the assessement of HER family members. All members of this group are reported to be expressed in urothelial cancer (27), but HER2 has been the most intensely studied, alone $(28,29,30)$ or in combination with other HER family members, especially EGFR $(31,32)$. Several papers reported that HER 2 positivity may predict muscle invasion in urothelial cancer of the urinary bladder $(33,34,35)$. Based on previous studies regarding HER2 involvement in tumor progression from bladder cancer, this oncoprotein was included in newly designed multiplatform biomarkers designed to be used in clinical practice to predict invasion and reccurence in patients with urothelial cancer $(36,37,38)$. Our data support the HER2 role in the local invasion of urothelial tumors, most of the cases scored as +2 and +3 being staged into $\mathrm{T} 3$ ( $\mathrm{a}$ or $\mathrm{b}$ ) group. Also, HER2 overexpression was correlated with an increase in the percentage of cases identified with lymphovascular invasion on histological specimens assessed in the present study. Our data were in concordance with the only paper found in the literature regarding the interconnection between HER2 overexpression and lymphovascular invasion. Bolenz and coworkers reported that HER2 positivity was significantly associated with the presence of lymphovascular invasion (39) and this oncoprotein overexpression was highly associated with an increased aggressiveness of the tumor and provided independent prognostic information for recurrence and mortality. A recent paper published by the same team (40) reported a complete remission of the urothelial carcinoma following third-line treatment with trastuzumab and gemcitabine in a patient with HER2 positive urothelial cancer initially unresponsive to cisplatin and vinflunine chemotherapies. These evidences are not widely accepted in the field of HER 2 research in urothelial carcinomas (41). Recent data reported that HER2 is overexpressed not only in primary urothelial cancers but also in their corresponding lymph node metastases $(29,42)$.

Based on previously published data and our own results, the study of the HER2 family in urothelial cancer seems to be a harder battle than cancer itself. There are currenlty more controversies than evidence for the use of HER2 as a therapeutic target in bladder cancer. Several reasons contribute to these unresolved issues in bladder cancer the most important of them being the unproper technical approach used for HER2 assessement together with a lack of a well standardised protocol of its interpretation specifically for bladder cancers overexpressing HER2. Our results sustain an extensive revision of HER2 assessement protocols in bladder based on criteria regarding immunohistochemical and in situ hybridisation use and interpretation as effective tools for HER2 validation as a molecular marker in urothelial cancer subtyping, an issue recently and frequently discussed $(43,44,45)$.

\section{Conclusion}

New immunohistochemical and FISH protocols should specifically be designed for urothelial carcinomas. IHC should remain the first step in this evaluation. Our results showed that all cases scored as +2 and +3 by IHC were confirmed by FISH analysis having gene amplification and this may be considered a strong reason supporting the patient selection for anti HER2 therapy based on immunohistochemistry only. Negative and +1 HER2-IHC scored cases represent a questionable issue in urothelial carcinomas. Our data support the recommendation of FISH analysis for these groups which seem to be underscored by immunohistochemistry restricted analysis. Cases scored as negative by HER2-IHC but found positive by FISH analysis may explain phenotypic switch in HER2 expression between primary tumor (negative for HER2 by IHC) and corresponding lymph node metastasis (in some cases strongly positive for HER2 by IHC).

\section{Conflicts of Interest}

No competing interests to declare.

\section{Acknowledgements}

The Authors would like to thank Dr. Amalia Raluca Ceausu for her technical excellence and to Victor Babes University of Medicine and Pharmacy Timisoara, Romania for its continuous financial and administrative support. Present study was supported by funds kindly provided by Victor Babes University of Medicine and Pharmacy Timisoara, Romania, through P-III-C5-PCFI-2017/2018-03 Internal grant-acronym UROVESSELS.

\section{References}

1 Marchio C, Balmativola D, Castiglione R, Annaratone L and Sapino A: Predictive pathology in the target therapy era in breast cancer. Curr Drug Targets 18: 4-12, 2016.

$2 \mathrm{Li} \mathrm{K}$ and Li J: Current molecular targeted therapy in advanced gastric cancer: A comprehensive review of therapeutic mechanism, clinical trials, and practical application. Gastroenterol Res Pract 2016: 4105615, 2016.

3 Urabe M, Ushiku T, Seto Y and Fukayama M: Pathologic response of HER2-positive gastric cancer to trastuzumab-based chemotherapy. Am J Surg Pathol 40: 1326-1333, 2016. 
4 Weng WH, Chen YT, Yu KJ, Chang YH, Chuang CK and Pang ST: Genetic alterations of HER genes in chromophobe renal cell carcinoma. Oncol Lett 11: 2111-2116, 2016.

5 Ross JS, Wang K, Khaira D, Ali SM, Fisher HA, Mian B, Nazeer T, Elvin JA, Palma N, Yelensky R, Lipson D, Miller VA, Stephens PJ, Subbiah V and Pal SK: Comprehensive genomic profiling of 295 cases of clinically advanced urothelial carcinoma of the urinary bladder reveals a high frequency of clinically relevant genomic alterations. Cancer 122: 702-711, 2016.

6 Huang SC, Ng KF, Lee SE, Chen KH, Yeh TS and Chen TC: HER2 testing in paired biopsy and excision specimens of gastric cancer: the reliability of the scoring system and the clinicopathological factors relevant to discordance. Gastric Cancer 19: 176-182, 2016.

7 Appert-Collin A, Hubert P, Crémel G and Bennasroune A: Role of ErbB receptors in cancer cell migration and invasion. Front Pharmacol 6: 283, 2015.

8 Mishra K, Behari A, Kapoor VK, Khan MS, Prakash S and Agrawal S: Platelet derived growth factor-B and human epidermal growth factor receptor-2 polymorphisms in gallbladder cancer. Asian Pac J Cancer Prev 16: 5647-5654, 2015.

9 Tschui J, Vassella E, Bandi N, Baumgartner U, Genitsch V, Rotzer D, Seiler R, Thalmann GN and Fleischmann A: Morphological and molecular characteristics of HER2 amplified urothelial bladder cancer. Virchows Arch 466: 703-710, 2015.

10 Gonzalez RS, Messing S, Tu X, McMahon LA and WhitneyMiller CL: immunohistochemistry as a surrogate for molecular subtyping of gastric adenocarcinoma. Hum Pathol 56: 16-21, 2016.

11 Junior PN, Neto RA and Forones NM: HER2 expression as a prognostic factor in metastatic gastric cancer. Arq Gastroenterol 53: 62-67, 2016.

12 Criscitiello C, Bagnardi V, Viale G, Disalvatore D, Rotmensz N, Esposito A, Goldhirsch A and Curigliano G: HER2 equivocal status in early breast cancer is not associated with higher risk of recurrence. Anticancer Res 36: 3537-3540,2016.

13 Amato M, Perrone G, Righi D, Pellegrini C, Rabitti C, Di Matteo F, Crucitti P, Caputo D, Coppola R, Tonini G, Santini D and Onetti Muda A.: HER2 status in gastric cancer: comparison between primary and distant metastatic disease. Pathol Oncol Res 23: 55-61, 2017.

14 Afzal M, Amir M, Hassan MJ, Hussain MS, Aziz MN, Murad S, Murtaza I, Anees M and Sultan A: Clinical role of HER2 gene amplification and chromosome 17: a study on 154 IHCequivocal cases of invasive breast carcinoma patients. Tumour Biol 37: 8665-8672, 2016.

15 Fan YS, Casas CE, Peng J, Watkins M, Fan L, Chapman J, Ikpatt OF, Gomez C, Zhao W and Reis IM: HER2 FISH classification of equivocal HER2 IHC breast cancers with use of the 2013 ASCO/CAP practice guideline. Breast Cancer Res Treat 155: 457-62, 2016.

16 Singh K, Tantravahi U, Lomme MM, Pasquariello T, Steinhoff M and Sung CJ: Updated 2013 College of American Pathologists/American Society of Clinical Oncology (CAP/ASCO) guideline recommendations for human epidermal growth factor receptor 2 (HER2) fluorescent in situ hybridization (FISH) testing increase HER2 positive and HER2 equivocal breast cancer cases; retrospective study of HER2 FISH results of 836 invasive breast cancers. Breast Cancer Res Treat 157: 405-411, 2016.
17 Raica M, Cîmpean AM, Ceausu RA, Fulga V, Nica C, Rudico L and Saptefrati L: Hormone receptors and HER2 expression in primary breast carcinoma and corresponding lymph node metastasis: do we need both? Anticancer Res 34: 1435-1440, 2014.

18 Park SR, Park YS, Ryu MH, Ryoo BY, Woo CG, Jung HY, Lee JH, Lee GH and Kang YK: Extra-gain of HER2-positive cases through HER2 reassessment in primary and metastatic sites in advanced gastric cancer with initially HER2-negative primary tumours: Results of GASTric cancer HER2 reassessment study 1 (GASTHER1). Eur J Cancer 53: 42-50, 2016.

19 Gutierrez C and Schiff R: HER 2:Biology, Detection, and Clinical Implications.Arch Pat Lab Med 135: 55-62, 2011.

20 King CR, Kraus MH and Aaronson SA: Amplification of a novel v-erbB-related gene in a human mammary carcinoma. Science 229: 974-976, 1985.

21 Hernández-Blanquisett A, Touya D, Strasser-Weippl K, Ruiz R, St Louis $\mathrm{J}$ and Goss P: Current and emerging therapies of HER2-positive metastatic breast cancer. Breast 29: 170-177, 2016.

22 Kümler I, Tuxen MK and Nielsen DL: A systematic review of dual targeting in HER2-positive breast cancer. Cancer Treat Rev 40: 259-270, 2014.

23 Kennedy SP, Hastings JF, Han JZ and Croucher DR: The underappreciated promiscuity of the epidermal growth factor receptor family. Front Cell Dev Biol 4: 88, 2016.

24 Recondo G Jr, de la Vega M, Galanternik F, Díaz-Cantón E, Leone BA and Leone JP: Novel approaches to target HER2positive breast cancer: trastuzumab emtansine. Cancer Manag Res 8: 57-65, 2016.

25 Goel S, Wang Q, Watt AC, Tolaney SM, Dillon DA, Li W, Ramm S, Palmer AC, Yuzugullu H, Varadan V, Tuck D, Harris LN, Wong KK, Liu XS,Sicinski P, Winer EP, Krop IE and Zhao JJ: Overcoming therapeutic resistance in HER2-positive breast cancers with CDK4/6 inhibitors. Cancer Cell 29: 255-269, 2016.

26 Grillo F, Fassan M, Sarocchi F, Fiocca R and Mastracci L: HER2 heterogeneity in gastric/gastroesophageal cancers: From benchside to practice. World J Gastroenterol 22: 5879-5887, 2016.

27 Black PC and Dinney CP: Growth factors and receptors as prognostic markers in urothelial carcinoma. Curr Urol Rep 9: 55-61, 2008.

28 Soria F, Moschini M, Haitel A, Wirth GJ, Gust KM, Briganti A, Rouprêt M, Klatte T, Hassler MR, Karakiewicz PI and Shariat SF: The effect of HER2 status on oncological outcomes of patients with invasive bladder cancer. Urol Oncol 34: 533.e1533.e10, 2016.

29 Nedjadi T, Al-Maghrabi J, Assidi M, Dallol A, Al-Kattabi H, Chaudhary A, Al-Sayyad A, Al-Ammari A, Abuzenadah A, Buhmeida A and Al-Qahtani M: Prognostic value of HER2 status in bladder transitional cell carcinoma revealed by both IHC and BDISH techniques. BMC Cancer 16: 653, 2016.

30 Aragon-Ching JB and Trump DL: Systemic therapy in muscleinvasive and metastatic bladder cancer: current trends and future promises. Future Oncol 12: 2049-2058, 2016.

31 Carlsson J, Wester K, De La Torre M, Malmström PU and Gårdmark T: EGFR-expression in primary urinary bladder cancer and corresponding metastases and the relation to HER2expression. On the possibility to target these receptors with radionuclides. Radiol Oncol 49: 50-58, 2015. 
32 Cerbone L, Sternberg CN, Sengeløv L, Agerbaek M, Van Herpen C, Marreaud S, Collette S, Zhang J and Daugaard G: Results from a phase I study of lapatinib with gemcitabine and cisplatin in advanced or metastatic bladder cancer: EORTC Trial 30061. Oncology 90: 21-28, 2016.

33 Ding W, Tong S, Gou Y, Sun C, Wang H, Chen Z, Tan J, Xu K, Xia $\mathrm{G}$ and Ding Q: Human epidermal growth factor receptor 2: a significant indicator for predicting progression in non-muscleinvasive bladder cancer especially in high-risk groups. World J Urol 33: 1951-1957, 2015.

34 Lim SD, Cho YM, Choi GS, Park HK, Paick SH, Kim WY, Kim SN and Yoon G: Clinical significance of substaging and HER2 expression in papillary nonmuscle invasive urothelial cancers of the urinary bladder. J Korean Med Sci 30: 1068-1077, 2015.

35 Chen PC, Yu HJ, Chang YH and Pan CC: HER2 amplification distinguishes a subset of non-muscle-invasive bladder cancers with a high risk of progression. J Clin Pathol 66: 113-119, 2013.

36 De Paoli M, Gogalic S, Sauer U, Preininger C, Pandha H, Simpson G, Horvath A and Marquette C: Multiplatform biomarker discovery for bladder cancer recurrence diagnosis. Dis Markers 2016: 4591910, 2016.

37 Kluth LA, Black PC, Bochner BH, Catto J, Lerner SP, Stenzl A, Sylvester R, Vickers AJ, Xylinas E and Shariat SF: Prognostic and prediction tools in bladder cancer: a comprehensive review of the literature. Eur Urol 68: 238-253, 2015.

38 De Paoli M, Perco P, Mühlberger I, Lukas A, Pandha H, Morgan R, Feng GJ and Marquette C: Disease map-based biomarker selection and pre-validation for bladder cancer diagnostic. Biomarkers 20: 328-337, 2015.

39 Bolenz C, Shariat SF, Karakiewicz PI, Ashfaq R, Ho R, Sagalowsky AI and Lotan Y: Human epidermal growth factor receptor 2 expression status provides independent prognostic information in patients with urothelial carcinoma of the urinary bladder. BJU Int 106: 1216-1222, 2010.
40 Wezel F, Erben P, Gaiser T, Budjan J, von Hardenberg J, Michel MS and Bolenz C: Complete and durable remission of human epidermal growth factor receptor 2-positive metastatic urothelial carcinoma following third-line treatment with trastuzumab and gemcitabine. Urol Int, 2016. Epub ahead of print.

41 Oudard S, Culine S, Vano Y, Goldwasser F, Théodore C, Nguyen T, Voog E, Banu E, Vieillefond A, Priou F, Deplanque G, Gravis G, Ravaud A, Vannetzel JM, Machiels JP, Muracciole X, Pichon MF, Bay JO, Elaidi R, Teghom C, Radvanyi F and Beuzeboc P: Multicentre randomised phase II trial of gemcitabine+platinum, with or without trastuzumab, in advanced or metastatic urothelial carcinoma overexpressing Her2. Eur J Cancer 51: 45-54, 2015.

42 Fleischmann A, Rotzer D, Seiler R, Studer UE and Thalmann GN: Her2 amplification is significantly more frequent in lymph node metastases from urothelial bladder cancer than in the primary tumours. Eur Urol 60: 350-357, 2011.

43 Mitra AP: Molecular substratification of bladder cancer: moving towards individualized patient management. Ther Adv Urol 8: 215-233, 2016.

44 Bartsch G, Mitra AP and Cote RJ: Expression profiling for bladder cancer: strategies to uncover prognostic factors. Expert Rev Anticancer Ther 10: 1945-1954,2010.

45 Adam RM and DeGraff DJ: Molecular mechanisms of squamous differentiation in urothelial cell carcinoma: a paradigm for molecular subtyping of urothelial cell carcinoma of the bladder. Urol Oncol 33: 444-450, 2015.
Received July 18, 2017

Revised August 1, 2017

Accepted August 2, 2017 